were also implicated as examples of when children are less likely to receive analgesia from practitioners.

Conclusion The pathway to improving care must be paved with an emphasis on improvements in practitioner education and training, offering alternatives to assessing pain in pre-verbal children, exploring the intranasal route of drug delivery in managing acute severe pain, and through robustly developing evidence-based guidelines that are practitioner friendly and patient-focused.

\section{G244(P) YOUNG PEOPLE GET ACTIVE! FOCUS GROUP INVOLVEMENT TO IMPROVE THE EXPERIENCE OF ADOLESCENT PAEDIATRIC PATIENTS IN EMERGENCY DEPARTMENTS}

doi:10.1136/archdischild-2013-304107.256

${ }^{1} \mathrm{~K}$ Sexton, ${ }^{2} \mathrm{P}$ Heinz, ${ }^{2} \mathrm{~K}$ Lothian. 'Clinical School, Cambridge University, Cambridge, UK; ${ }^{2}$ Department of Paediatrics, Cambridge University Hospitals NHS Foundation Trust, Cambridge, UK

Recent publication of 'Standards for Children and Young People in Emergency Care Settings' has brought involvement of young people in service design into the spotlight. Whilst many studies have focussed on parental opinion, our project aimed to involve ACTIVE, a young peoples' focus group. This group of young people aged 8 18 years was set up 4 years ago with the aim to improve services for children at our hospital, especially for adolescents.

Methods The group defined their priorities for emergency department (ED) care in a brainstorming session followed by a visit to the $\mathrm{ED}$ in the form of a simulated patient journey.

Results ACTIVE identified speed of assessment, clear communication, prompt pain relief and attention to their comfort needs as well as privacy as their main priorities. On visiting the ED they pointed out areas for improvement as follows: paediatric nursing staff at pre-triage, decoration or lack thereof in certain areas of the department (but also positive comments on where this was done well), lack of privacy in defined areas and ways to communicate waiting times effectively and accurately. Whilst a dedicated 'teenage room' was not felt to be important, the need for a quiet waiting and clinical area was stressed.

Outcome and conclusion Studies have shown that adolescent satisfaction in the ED is often lower than that of adult patients. Young peoples' focus groups are an effective resource in the design of services and in the case of our centre have led to direct input into the re-design of our paediatric ED area (the proposed plans will available for inspection). Feedback to young service users is important to encourage further participation and to ensure that they are aware of how their suggestions will be used.

\section{G245(P) PITFALLS IN WEIGHT ESTIMATION}

doi:10.1136/archdischild-2013-304107.257

G Harlow, R Jayatunga. Department of Paediatrics, Sandwell Hospital, Sandwell and West Birmingham NHS Trust, West Bromwich, UK

Children and infants of different age and weight respond differently to drugs. Special care is needed in the calculation of drug doses to reduce and prevent the risk of toxicity. The 2011 Advanced Paediatric Life Support (APLS) guideline, 5th edition, includes an updated method for weight estimation for emergency situations[1].

Aims We aim to study our population of patients to determine whether their actual weights are congruent with the updated APLS weight estimation. We also compare with the 2005 APLS weight estimate calculation[2].

Method Prospective audit at a large two-site NHS trust with a 23-hour paediatric assessment unit and two in-patient wards. The catchment population for our study has a higher proportion of population in lower socioeconomic groups than the national average[3]. The age, basic diagnosis and weight of consecutive presenting

\section{Abstract G245(P) Table 1}

\begin{tabular}{|c|c|c|c|c|}
\hline $\begin{array}{c}\text { Age } \\
\text { (years) }\end{array}$ & $\begin{array}{l}\text { Number of } \\
\text { patients }\end{array}$ & $\begin{array}{l}\text { Mean } \\
\text { weight } \\
(\mathrm{kg})\end{array}$ & $\begin{array}{c}\text { Mean }(95 \% \text { CI) } \\
\text { percentage weight } \\
\text { difference } 2005 \text { APLS } \\
\text { formula }\end{array}$ & $\begin{array}{l}\text { Mean }(95 \% \mathrm{CI}) \\
\text { percentage weight } \\
\text { difference } \\
2011 \mathrm{APLS} \\
\text { formulae }\end{array}$ \\
\hline $\begin{array}{c}\text { Less } \\
\text { than } 1\end{array}$ & 33 & 6.55 & $\mathrm{n} / \mathrm{a}$ & $-8 \%(-2--15)$ \\
\hline 1 & 17 & 10.65 & $-6 \%(-16-3)$ & $-6 \%(-16-3)$ \\
\hline 2 & 7 & 15.23 & $-27 \%(-49--5)$ & $-27 \%(-49--5)$ \\
\hline 3 & 11 & 17.44 & $-25 \%(-38--11)$ & $-25 \%(-38--11)$ \\
\hline 4 & 8 & 18.36 & $-15 \%(-41-12)$ & $-15 \%(-41-12)$ \\
\hline 5 & 10 & 21.58 & $-20 \%(-40-0)$ & $-20 \%(-40-0)$ \\
\hline 6 & 13 & 22.97 & $-15 \%(-26--4)$ & $8 \%(-1-17)$ \\
\hline 7 & 20 & 27.65 & $-26 \%(-43--8)$ & $1 \%(-13-15)$ \\
\hline 8 & 5 & 34.98 & $-46 \%(-62--29)$ & $-13 \%(-26-0)$ \\
\hline 9 & 11 & 37.17 & $-43 \%(-68--18)$ & $-9 \%(-28-10)$ \\
\hline 10 & 5 & 36.26 & $-30 \%(-45--14)$ & $2 \%(-9-13)$ \\
\hline 11 & 12 & 37.77 & $\mathrm{n} / \mathrm{a}$ & $6 \%(-17-28)$ \\
\hline 12 & 14 & 42.14 & $\mathrm{n} / \mathrm{a}$ & $2 \%(-16-20)$ \\
\hline
\end{tabular}

children between 1 month and 12 years were collected for 166 patients in December 2012. We aim to collect data to March 2013 with an estimated sample size of 500. Children were weighed on Seca baby/standing/chair scales (Seca, Hamburg, Germany) with children under two naked and over two wearing minimum clothing without shoes. Percentage weight difference between child's actual weight and their expected weight was calculated using both the 2005 APLS formula, weight $(\mathrm{kg})=($ age +4$) \times 2$ and the 2011 formulae: $1-12$ months: weight $(\mathrm{kg})=(0.5 \times$ age in months $)+4 ; 1-5$ years: weight $(\mathrm{kg})=(2 \times$ age in years $)+8 ; 6-12$ years: weight $(\mathrm{kg})=(3 \times$ age in years) +7

Results Table 1: Mean weight differences by age

Preliminary results outlined in Table 1 demonstrate that although the 2011 APLS calculation is better for weight estimation in our 6-12 years age group than the 2005 calculation, there is still the potential for significant underestimation of weight in all ages.

Conclusion Weight estimation is extremely important for paediatric resuscitation and emergency treatment. However, across all age groups weight estimation is no substitute for establishing the child's actual weight at the earliest opportunity.

\section{REFERENCES}

1. Advanced Life Support Group. APLS, Fifth Edition. Blackwell 2011.

2. Advanced Life Support Group. APLS, Fourth Edition. Blackwell 2005.

3. 2011 Census: Key Statistics for local authorities in England and Wales. Office for National Statistics; December 2012.

\section{G246(P) CHILDREN WITH CHEST PAIN - A CAUSE FOR ANXIETY BUT IS IT AN EMERGENCY?}

doi:10.1136/archdischild-2013-304107.258

G Mujtaba, J Awan, C Martin. Paediatric Emergency Department, Tallaght Hospital, Dublin, Ireland

Background Chest pain (CP) in children is a common complaint in emergency departments, general paediatric clinics, and paediatric cardiology clinics. It can be a source of anxiety for parents, patient and physicians and can lead to a school and sports absenteeism. A thorough history and physical examination usually can determine the cause and differentiate patients who require acute intervention from those who can be managed with advice and reassurance.

Aim To review the presentation, and management of children presenting with chest pain to a tertiary level teaching hospital over a 12 month period. To assess diagnosis, investigations, treatment and follow up. 
Methods Retrospective data was collected on all children attending emergency department with triage complaint of chest pain using the Emergency department Information system.

Results 134 children were identified

Mean age: 11.66 years [range: $3-16 y e a r s] .80(60 \%)$ were male and $54(40 \%)$ were females. Median duration of chest pain was 2 days and half of children presented within 48 hours of pain onset.

Documentation was poor with no recorded history of cough, fever or shortness of breath in almost half of the presentations. The following specific cardiac symptoms were not recorded; radiation to arm (73.9\%), Radiation to back (76\%), Dizziness (82\%), Collapse (88\%) and Palpitations (73\%). No mention drug abuse in $100 \%$

Examination findings revealed $93 \%$ had no murmur and $99.3 \%$ had normal $\mathrm{O}_{2}$ Sats on arrival.

Investigations - ECG in $82 \%$ and was abnormal in $6 \%$. Chest $\mathrm{X}$-ray in $77 \%$ and it was abnormal in 10\%. FBC was abnormal in $<1 \%$ of patients. Troponin was done in $17 \%$ and none of these had abnormal result. D-Dimer was raised in only 2 out of 6 patients $(1.5 \%)$.

Most Common Diagnoses were Musculoskeletal 26.9\%, Costochondritis $23.1 \%$ Idiopathic $14.1 \%$ and Pneumonia $8.2 \%$. Only 1 child had cardiac diagnosis $0.8 \%$ required admission while $92 \%$ were discharged home.

Conclusions Review of 1 year of ED visits revealed that CP in children is a reasonably common complaint and is associated with tremendous anxiety and resource utilisation. There is a need for better documentation of history and examination findings. Yield from Investigations is low and should be reserved for at risk patients.

\section{G247(P) BRIDGING THE GAP BETWEEN FAMILIES, PRIMARY AND SECONDARY CARE}

doi:10.1136/archdischild-2013-304107.259

${ }^{1,2} \mathrm{C}$ Geraghty, ${ }^{1,2} \mathrm{~S}$ Banks, ${ }^{2} \mathrm{C}$ Bevan. 'Brighton and Sussex Medical School, Sussex University, Brighton, UK; ${ }^{2}$ Children's Emergency Department, Royal Alexandra Children's Hospital, Brighton, UK

Children's Emergency Department's (CED) are seeing an increasing number of primary care problems. The most worrying group are the febrile young children and the concern of a serious occult bacterial infection. We set out to analyse this group as a tool for future targeted education and support for our department, parents and primary care. Methods 100 patients aged $0-5 y e a r s$ with a temperature of $>38.0$ at presentation were reviewed. They were analysed using the febrile children NICE guidelines and assigned a risk group.LR- Low, IRIntermediate and HR High Risk.

Results (see table)

The majority $61 \%$ were LR (59\% 1-3yrs, $29 \%<1 \mathrm{yr}$ )

$68 \%$ were self referrals. $32 \%$ were the GP referrals a third being LR and $82 \%$ were discharged home.14\% presented via ambulance, $57 \%$ were LR and $71 \%$ were discharged home.

The majority had no investigations; a third of children in the intermediate and high risk still had no investigations.

Of all diagnoses made, $46 \%$ were viral illnesses of which $74 \%$ did not receive antibiotics.

$75 \%$ were discharged home with no investigations. The younger the children and the higher the risk group, the more likely that investigations would be performed. Of the $25 \%$ requiring admission $73 \%$ had no investigations.

The majority of patients required review.

Overall the commonest diagnosis was viral infection (46\%) of which $26 \%$ still received antibiotics.

Surprisingly there were almost $100 \%$ of patients that were vaccinated.

Conclusions Parents are concerned about fever in young children and present frequently straight to CED. GPs also refer many patients with fever whom are LR category. However, in CED these
Abstract G247(P) Table 1

\begin{tabular}{|l|l|l|l|l|l|l|l|l|l|}
\hline & \multicolumn{3}{|c|}{$<$ year } & \multicolumn{3}{c|}{ 1-years } & \multicolumn{3}{c|}{ 3 years } \\
\hline Number & \multicolumn{3}{|c|}{29} & \multicolumn{3}{c|}{56} & \multicolumn{3}{c|}{15} \\
\hline Level of risk & LR & IR & HR & LR & IR & HR & LR & IR & HR \\
\hline Number & 15 & 6 & 8 & 35 & 15 & 6 & 13 & 2 & 0 \\
\hline No Investigations (\%) & $87 \%$ & $33 \%$ & $38 \%$ & $74 \%$ & $67 \%$ & $33 \%$ & $58 \%$ & $50 \%$ & 0 \\
\hline Discharged(\%) & $90 \%$ & $50 \%$ & $37 \%$ & $94 \%$ & $74 \%$ & $16 \%$ & $92 \%$ & $50 \%$ & 0 \\
\hline $\begin{array}{l}\text { Required senior } \\
\text { review }\end{array}$ & $93 \%$ & $75 \%$ & $50 \%$ & $71 \%$ & $6 \% \%$ & $100 \%$ & $70 \%$ & $100 \%$ & 0 \\
\hline & & & & & & & & & \\
\hline Vaccinated & $100 \%$ & $100 \%$ & $57 \%$ & $82 \%$ & $100 \%$ & $100 \%$ & $100 \%$ & $100 \%$ & 0 \\
\hline
\end{tabular}

children still require senior review although the majority no do not get investigated and are discharged. This study has helped instigate a change in practise of the local GP practises to prioritise the $<5$ year olds and to re-open the primary care unit within the hospital grounds. It has also enabled us to provide more senior cover in CED for review and timely discharge of patients without inappropriate investigations.

\section{G248(P) CAN A COMBINED TOOL WITH PAEDIATRIC ILLNESS SEVERITY ASSESSMEENT AND PAEDIATRIC EARLY WARNING SCORE BE USED AS A SAFETY TOOL FOR DISCHARGE OF PATIENTS FROM OBSERVATION AND ASSESSMENT UNIT?}

doi:10.1136/archdischild-2013-304107.260

'R Puttha, 'N Nandakumar, 'S Langworth, ${ }^{2} \mathrm{R}$ Thalava, 'L Yeung. 'Paediatrics, University Hospitals Of South Manchester, Manchester, UK; ${ }^{2}$ Orthopaedics, Tameside General Hospital NHS Foundation Trust, Manchester, UK

Aim Our aim was to evaluate if Paediatric Illness Severity Assessment (PISA) and PEWS can be used as a combined tool for safe discharge of patients from Paediatric Observation and Assessment unit (POAU).

Method We reviewed the PISA and PEWS scoring on patients attending our POAU over a busy winter on three randomised days. All patients routinely had PEWS assessed by nursing staff at the time of admission, discharge and as needed in between these two. PISA was calculated from the clinical notes. The combined tool was used to assess whether patient needed admission or discharged home. If discharged home, data was collected if there were any complications or readmissions.

Results A total of 52 patients were studied. Their age range varied from 1 day to 15 years. 37 patients were discharged home and 15 were admitted to the hospital. All of the children who were discharged had an initial PEWS score of or less than 4 or had good response with the PEWS score dropping to 0 to 2 with intervention, while their PISA grading suggested mild or moderate risk. There were no major complications in those who were discharged home. One patient was readmitted, which the parent was already cautioned. 5 patients who were admitted to the hospital had PEWS score of 0 to 2 but their PISA grading was moderate to severe risk, indicating the need for hospital admission. All those with an initial PEWS scoring above 4 or those with persistent score above 3 needed hospital admission and their PISA grading suggested moderate risk. The combined PISA and PEWS tool, in our study, when used for discharge, had a sensitivity (the probability of the child being discharged) of $100 \%$ and specificity of $97.3 \%$ with a PEWS scoring below 2 and PISA grading of mild risk. 